\title{
Interdecadal Variability of Tropical Cyclone Activity in the Western North Pacific
}

\author{
By Michiaki Yumoto and Tomonori Matsuura \\ National Research Institute for Earth Science and Disaster Prevention, Tsukuba, Japan
}

(Manuscript received 24 January 2000, in revised form 6 October 2000)

\begin{abstract}
Investigating the variability of tropical cyclone (TC) activity in the western North Pacific (WNP) during the 49-yr period 1951-99, interdecadal variation is confirmed. Two kinds of periods are identified in this study: High Frequency Period (HFP) when TC activity is enhanced, and Low Frequency Period (LFP) when TC activity is reduced. Significant differences in the number of TCs between HFP and LFP are found in the typhoon season from July through October. The differences in TC activity between HFP and LFP are also found in the areal extent of TC genesis. The area of TC genesis in HFPs extends more to the east than that in LFPs. Seasonal conditions of sea surface temperature (SST), relative vorticity at 850 $\mathrm{hPa}$, divergence at $200 \mathrm{hPa}$ and outgoing longwave radiation (OLR) are analyzed to discuss the differences in TC activity between the two kinds of periods. Both oceanic and atmospheric conditions differ between HFP and LFP with statistical significance. In HFP, the SST in the eastern WNP (east of $150^{\circ} \mathrm{E}$ ) is higher, and the convective activity at the area from $10^{\circ} \mathrm{N}$ to $20^{\circ} \mathrm{N}$ is stronger, than in LFP. These results show that the atmospheric and oceanic circumstances for HFPs in the tropical and subtropical WNP enhance the genesis of TCs in comparison with those for LFPs. It is suggested that the variability of SST in the Pacific, and that of large-scale atmospheric circulation are the main causes of the interdecadal variability of TC activity.
\end{abstract}

\section{Introduction}

Countries in Southeast Asia including Japan are often hit by several tropical cyclones (TCs) with maximum sustained surface wind over $17.2 \mathrm{~m} \mathrm{~s}^{-1}$ every year. The heavy wind and rainfall from TCs lead to serious disasters, such as high tides, flooding, landslides, and so on. These disasters cause great loss of life. The annual average number of TCs is 27.8 in the western North Pacific (WNP, the sea area from $100^{\circ} \mathrm{E}$ to $180^{\circ}$ in the Northern Hemisphere) for the 30-yr period 1961-90. This average represents almost one-third of all TCs generated throughout the world. Thus, the WNP is the most

Corresponding author: Michiaki Yumoto, National Research Institute for Earth Science and Disaster Prevention, 3-1 Tennoudai, Tsukuba 305-0006, Japan.

E-mail: yumoto@bosai.go.jp

(C)2001, Meteorological Society of Japan active basin of TC genesis.

Some researchers have described the long-term variability of TC activity in the WNP. Aoki (1983, 1985) investigated the geographical and long-term variability of $\mathrm{TC}$ activity from a climatological standpoint. He described important differences in patterns of $500 \mathrm{hPa}$ geopotential height, cloudiness and SST between frequent/infrequent months of TC genesis. He concluded that the variation of SST had an effect on the frequency of TC genesis through the large-scale general circulation of the atmosphere over a long-term time scale. Lander (1994) and Chan and Shi (1996) also noted that the annual numbers of TCs in the WNP were high in the $1960 \mathrm{~s}$, decreased in the 1970s, and then gradually increased in the $1980 \mathrm{~s}$. It is unknown, however, why the long-term variability of TC activity occurs.

TC genesis is affected by both conditions of the ocean and the atmosphere in the tropical and sub- 
tropical regions. Gray (1968) found six factors of atmospheric and oceanic conditions for TC genesis based on observational analysis. Gray's six factors are: (1) high sea surface temperature (SST); (2) effect of the Coriolis force; (3) above-average relative vorticity in the lower troposphere; (4) weak vertical wind shear; (5) conditional instability; and, (6) above-average moisture in low- and middle-levels of the troposphere. In particular, high SSTs prepare a condition to effectively supply moisture into the atmosphere, and hence, it is an important factor in inducing deep convection (cf. Graham and Barnett 1987). SSTs in the tropical and subtropical WNP (equatorward of $20^{\circ} \mathrm{N}$ ) are generally high throughout the year; - their variability is smaller than that in any other basin. Therefore, in the WNP, TCs do occasionally develop, even in boreal winters (Raper 1993). With respect to atmospheric conditions, the development of TCs depends on the large-scale circulation rather than on the characteristics of the mesoscale system (McBride and Zehr 1981). Ritchie and Holland (1999) explored the nature of the large-scale environment in relation to TC genesis, and showed that the behavior of the monsoon trough, and the monsoon confluence region, plays a crucial role in generating $\mathrm{TCs}$.

Since the dynamic and thermodynamic environments of both the ocean and the atmosphere change with respect to long-term variations on the global scale, TC activity in the WNP may also be influenced by such changes, both directly and indirectly. There are two prominent variations on the order of a few to several years: the El Niño-Southern Oscillation (ENSO); and, the quasi-biennial oscillation (QBO). The relationship between such oscillations and TC activity in the WNP has been discussed in many studies. For instance, the ENSO cycle plays a major role in the interannual fluctuation of the annual mean genesis location of TCs in the WNP (Lander 1994; Matsuura et al. 1999). Concerning the relationship between TC activity and the QBO, $\mathrm{TC}$ activity in the Atlantic is more frequent during the westerly phase of the QBO (Gray 1984; Shapiro 1989; Lander and Guard 1998). Chan (1995) also suggested that the westerly phase - the QBO - corresponds to an increase in TC activity in the WNP. Lander and Guard (1998) showed, however, that the annual number of TCs in the WNP is not significantly correlated with the QBO, and that it did not increase during the westerly phase of the QBO.

There is a clear trend in the time series of $\mathrm{TC}$ activity in the WNP, as has been suggested. Com- parisons of the oceanic and atmospheric environments between the active and inactive periods of TC genesis may give us important and useful suggestions by which we can forecast long-term activity of TCs statistically. This study aims to discuss the relationship between interdecadal variability of TC activity in the WNP, and the variability of the oceanic and atmospheric conditions.

This study uses the data of TC activity in the WNP from the monthly Geophysical Review issued by the Japan Meteorological Agency (JMA) from 1991 to 1999, and Tropical Cyclone Tracks in the Western North Pacific 1951-1990 by the Regional Specialized Meteorological Centers (RSMC) TokyoTyphoon Center (1992). Monthly mean global SST data used in this study is the National Center for Environmental Prediction (NCEP) Reynolds Historical Reconstructed SST data set on a $2^{\circ} \times 2^{\circ}$ grid. Monthly mean global relative vorticity, divergence and outgoing longwave radiation (OLR) data are from the NCEP/ National Center for Atmospheric Research (NCAR) Reanalysis data set on a $2.5^{\circ} \times 2.5^{\circ}$ grid (Kalnay et al. 1996).

\section{Interdecadal variability in the frequency of TC genesis}

\subsection{High frequency periods and low frequency pe- riods}

Figure 1 shows a time series of the annual number of TCs in the WNP during the 49-yr period 1951-99. The annual number of TCs varies with large amplitude; - the maximum number was 39 in 1967, and the minimum number was 16 in 1998. The time series of the annual number of TCs shows two broad peaks: one in the mid-1960s, and the other in the early-1990s. A broad trough is evident in the mid-1970s. Two peaks and a trough are emphasized by smoothing the time series using a method of running medians known as 4(3RSR) $2 \mathrm{H}$ twice (cf., Chapters 7 and 16 of Tukey 1977; Chapter 6 of Velleman and Hoaglin 1981; Becker et al. 1988). The smoothing of annual numbers of TCs shows that two periods of higher TC activity are the 12-yr period 1961-72, and the 9-yr period 198694. The other periods, the $10-y r$ period $1951-60$ and the 13-yr period 1973-85, are remarkably inactive.

In this paper, the period of higher TC activity is called High Frequency Period (HFP) and the opposite period is called Low Frequency Period (LFP). The two HFPs and the two LFPs are referred to as 


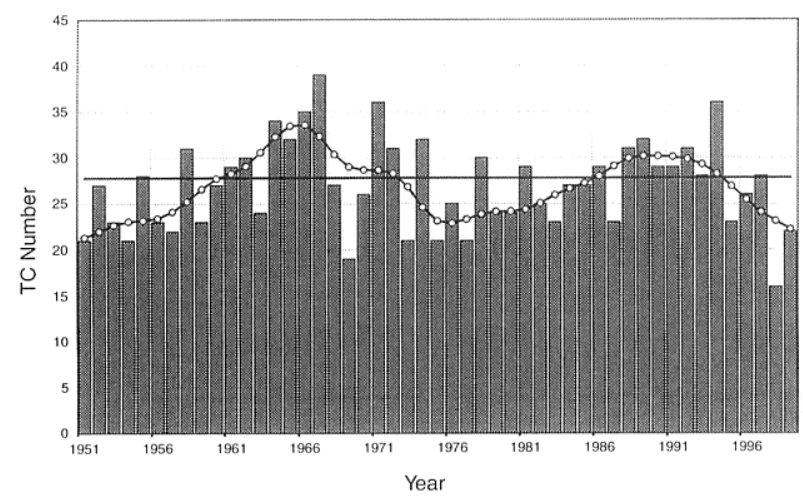

Fig. 1. Annual number of TCs (bar chart) and smoothed annual number of tropical cyclone determined by the method of running medians (line graph) during the 49yr period 1951-99.

L5160, H6172, L7385, and H8694 in the ascending order of the year. The differences for three combinations of two consecutive periods are H6172 L5160, L7385-H6172, and H8694-L7385. These are referred to as DIF-1, DIF-2, and DIF-3, respectively, hereafter.

The smoothing also shows that the annual number of TCs has decreased during the last 5 years from 1995 to 1999. However, we have not designated the period in and after 1995 as the third LFP, because the 5-yr period is only half of other LFPs.

\subsection{TC frequencies in HFPs and LFPs}

The average number of TCs in L5160 was 24.6 per year. The minimum annual number in this period was 21 in 1951 and 1954, while the maximum was 31 in 1958. Six years $(1951,1953-54,1956-57$, and 1959) had 23 or less TCs. The others (1952, 1955,1958 , and 1960) had 27 or more TCs. There is an interannual variation that indicates comparatively abundant genesis of TCs every $2-3$ years in L5160.

The average number of TCs in H6172 was 30.2 per year. The maximum annual number in this period was 39 in 1967 and the minimum was 19 in 1969. The difference between the maximum and minimum number in H6172 is larger than that of the other three periods. The annual number of TCs during the 6-year period 1964-67, 1971-72 exceeded 30, while the annual numbers in 1963 and the 3-yr period 1968-70 were below normal.

In L7385, the average number of TCs was 25.3 per year. The minimum annual number in this period is 21 in 1973, 1975 and 1977. The maximum was 32 in 1974. The annual numbers in 1978 and 1981 were 29 and 30, respectively. For L7385, the interannual variation shows that the annual number exceeding 27 also appears every $3-4$ years. The smoothing in Fig. 1 indicates that the annual number of TCs gradually increased after 1976. While the varying range of the annual number of TCs was large in early L7385, it became smaller and smaller with time. In the final two years of L7385, each annual number of TCs was 27 , which was near normal.

In H8694, the average number of TCs was 29.8 per year. TCs above normal formed during the 7yr period 1988-94. This result contrasts with the inactivity of TCs over the Atlantic during the 5-yr period 1991-94 (Landsea et al. 1996). The maximum annual number in this period was 36 during 1994. Thirty of those TCs occurred during the 4month period from July to October, the so-called "typhoon season." This frequency is 11 above the average number of TCs in the typhoon season, and is the maximum number for the season during the 49-yr period 1951-99. On the other hand, the annual number of TCs in 1987 was 23, which was the only value below normal in this period.

Within the annual variation of the monthly number of TCs, the maximum number of TC genesis events in the WNP occurs in August and the minimum in February (cf., Fig. 2). The monthly average number of TCs for August is 5.7, and that for February is 0.3 , - based on the data of the monthly number of TCs during the 30-yr period 1961-90. The comparison of the monthly average number between the two kinds of periods reveal that the difference between HFP and LFP appears clearly in

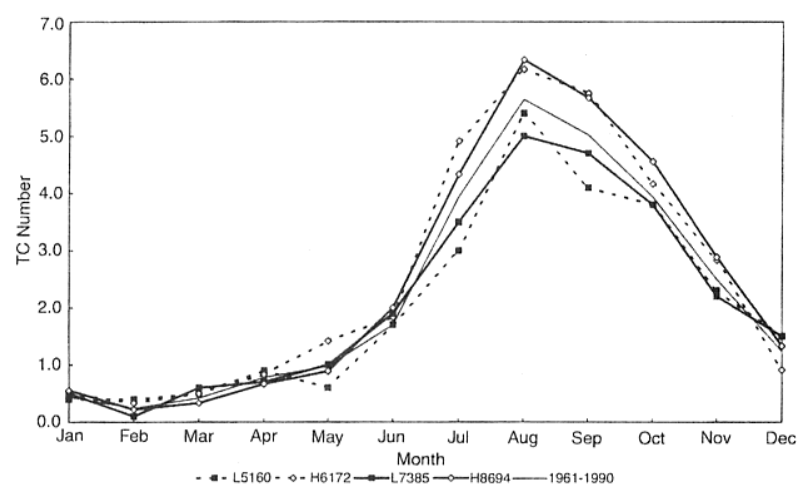

Fig. 2. Monthly average numbers of TCs for each frequency period. 
Table 1. Mean genesis location of TCs in each frequency period.

\begin{tabular}{lcccc}
\hline & L5160 & H6172 & L7385 & H8694 \\
\hline Latitude & $18.0(5.6)$ & $18.4(5.6)$ & $18.5(5.5)$ & $17.9(5.4)$ \\
Longitude & $137.1(13.5)$ & $139.1(15.8)$ & $135.1(14.5)$ & $139.0(16.2)$ \\
\hline
\end{tabular}

*Value in parenthesis is standard deviation.

the 4 months of the typhoon season (Fig. 2). There are no apparent differences in the monthly average numbers among any combination of periods in "offtyphoon seasons" from March to June, and from November to February. Thus, the difference in the annual number between HFP and LFP mainly comes from the total TCs in the typhoon season. Each monthly average number of TCs in HFPs is higher than that in LFPs. The monthly average number of TCs in August of L5160 is almost equal to the monthly average number of TCs in August during the 30-yr period 1961-90. This is caused by 10 TCs in August of 1960. This number, 10 TCs in a month, is the maximum monthly number during the 49-yr period 1951-99. The monthly average number of TCs in August of L5160 - except for 1960 - is 4.9 , and this value is equal to the monthly average number of TCs in August of L7385. Figure 3 shows two time series of the annual number of TCs and the number of TCs in the typhoon season. The variance of the number of TCs in the typhoon season is similar to that of the annual number of TCs. Correlation is also high $(0.87)$ between the annual number of TCs, and the number of TCs in the typhoon season. Therefore, we discuss the interdecadal variation of TC activity by focusing on that in the typhoon season from July to October.

The comparison of TC genesis locations between the two kinds of periods of the typhoon season shows that the area of TC genesis shifts more eastward in HFPs than in LFPs (see Fig. 4). The mean genesis locations of HFPs shift to the east from those of LFPs (Table 1). The mean genesis location in L7385 shifts farthest west among the four periods. As shown in the panel of L7385 of Fig. 4, many TCs occurred over the South China Sea in L7385.

The majority of TC geneses concentrate in an area of weak vertical shear, which is one of Gray's

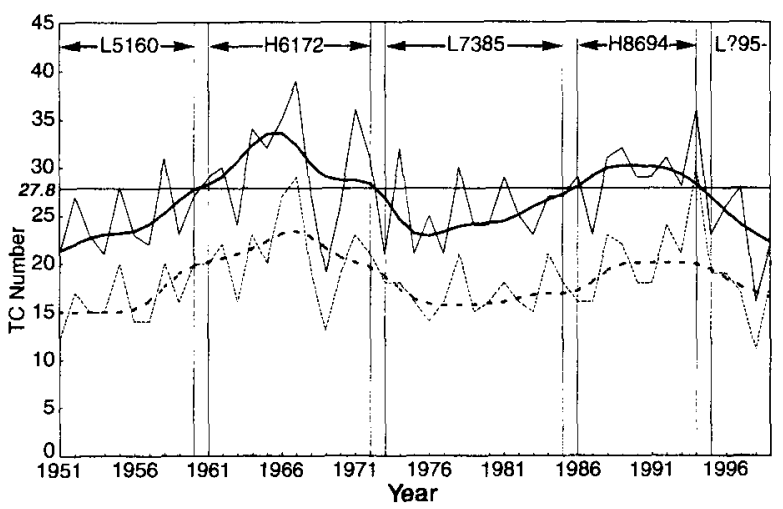

Fig. 3. Time series of the number of TCs during the 49-yr period 1951-99. Solid and dashed lines indicate annual numbers and numbers during the typhoon season, respectively. Heavy solid and dashed lines indicate smoothed number of both time series, respectively.

six factors related to TC genesis, as shown in Fig. 4. However, several TCs occur in the area of relatively strong vertical shear. TCs often occur in the South China Sea and off the east coast of the Philippines, where the vertical shear of the zonal wind is relatively strong. In these regions, horizontal positive relative-vorticity in the atmospheric lower layer is strong. Thus, TCs are formed in two regions with difference environmental conditions: one where vertical shear of the zonal wind is weak; and, the other where horizontal positive relativevorticity in the atmospheric lower layer is strong. Therefore, it may be possible to divide the genesis of TCs into two types, using the environmental conditions at the TC genesis location.

Figure 5 shows the difference of average number of TCs between two consecutive periods in each 10degree latitude and longitude square. Two panels of DIF -1 and DIF -3 have more areas stained by 

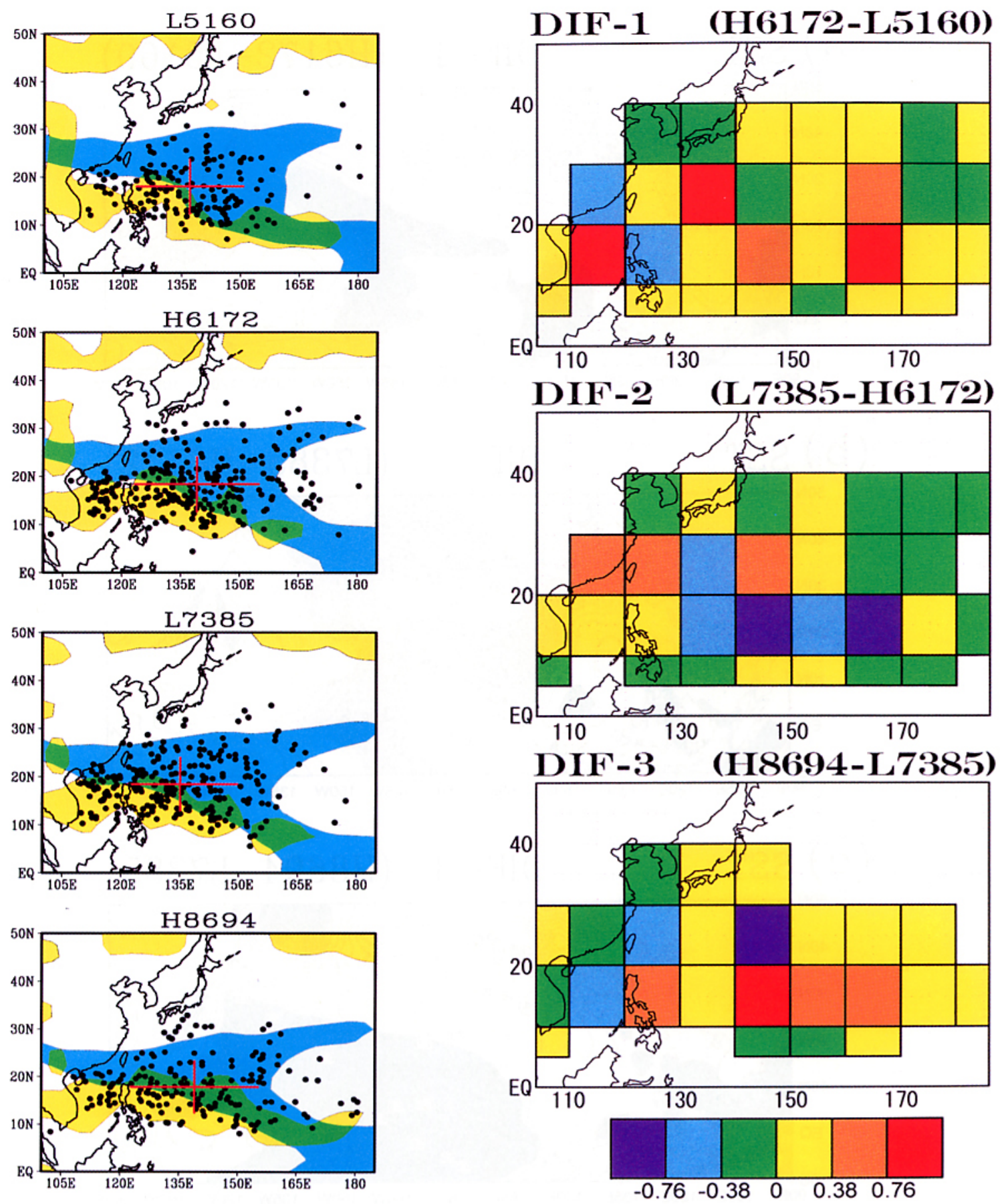

Fig. 4. Genesis locations of TCs, relative vorticity at $850 \mathrm{hPa}$ and vertical shear of the zonal wind during the typhoon season for each of 4 frequency periods. Yellow area is relatively strong vorticity over $3 \times 10^{-6} \mathrm{~s}^{-1}$. Blue area is weak vertical shear between $-5 \mathrm{~m} \mathrm{~s}^{-1}$ and $5 \mathrm{~m} \mathrm{~s}^{-1}$. Green area is both relatively strong vorticity and weak vertical shear.

Fig. 5. The difference of the incidence of tropical cyclone formation for each region for DIF-1, DIF-2, and DIF-3. Colors of yellow, orange and red (of green, blue and purple) depict the areas where the difference of the mean number of TCs is positive (negative). Values of \pm 0.38 and \pm 0.76 are $\pm \sigma$ and $\pm 2 \sigma$ of the difference of the average number of TCs, respectively. 

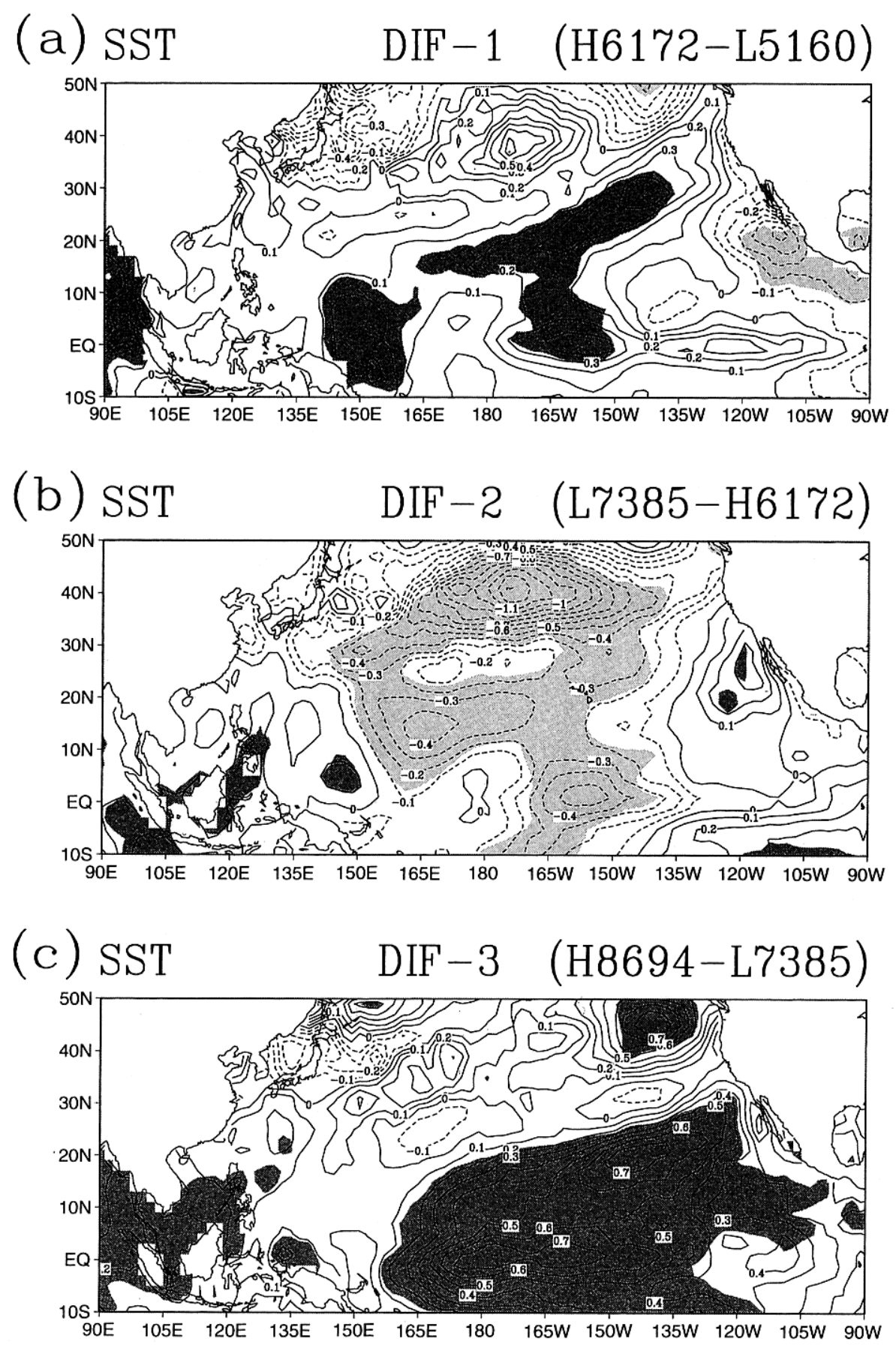

Fig. 6. Distribution of the differences of SSTs for DIF-1, DIF-2, and DIF-3. Shaded areas are statistically significant at $95 \%$ (dark shaded for anomalous positive SST and light shaded for anomalous negative SST). Contour interval is $0.2{ }^{\circ} \mathrm{C}$. 
warm colors than those by cold colors, respectively. These panels show that the number of TCs between $10^{\circ} \mathrm{N}-20^{\circ} \mathrm{N}, 130^{\circ} \mathrm{E}-170^{\circ} \mathrm{E}$ increases (decreases) in HFPs (LFPs). This relationship is not observed in the area $20^{\circ} \mathrm{N}-30^{\circ} \mathrm{N}, 140^{\circ} \mathrm{E}-150^{\circ} \mathrm{E}$.

\section{Variability of oceanic and atmospheric conditions in the WNP}

In order to understand the variations between HFP and LFP with respect to both oceanic and atmospheric conditions that are closely related to $\mathrm{TC}$ genesis, SST, relative vorticity at $850 \mathrm{hPa}$, divergence at $200 \mathrm{hPa}$, and outgoing longwave radiation (OLR) in the WNP are examined during the typhoon season. We have calculated differences of these physical quantities for three combinations: DIF-1 (H6172-L5160), DIF-2 (L7385-H6172), and DIF-3 (H8694-L7385).

\subsection{Variation of sea surface temperature (SST)}

Figure 6 shows differences of SST during the typhoon season for DIF-1, DIF-2, and DIF-3. In general, differences of SST are small east of the Philippine (between $120^{\circ} \mathrm{E}$ and $140^{\circ} \mathrm{E}$ ). That is, the SST during LFP is almost the same as that during HFP in the Philippine Sea, and oceanic conditions are favorable for TC genesis in spite of LFP.

The difference field for DIF-1 (Fig. 6a) is characterized by anomalous positive SSTs with statistical significance of $95 \%$ in the central portion of the tropical WNP $\left(0^{\circ}-10^{\circ} \mathrm{N}, 140^{\circ} \mathrm{E}-160^{\circ} \mathrm{E}\right)$. Figure $6 \mathrm{a}$ also indicates anomalous positive SST with statistical significance in the area $10^{\circ} \mathrm{N}-20^{\circ} \mathrm{N}, 165^{\circ} \mathrm{E}-$ $155^{\circ} \mathrm{W}$, which extends northeast of the Hawaii Islands.

The difference field for DIF-2 generally indicates anomalous negative SSTs in the central Pacific during the typhoon season (Fig. 6b). In particular, anomalous negative SSTs with statistical significance of $95 \%$ spread over the area $10^{\circ} \mathrm{N}-20^{\circ} \mathrm{N}, 140^{\circ}$ $\mathrm{E}-160^{\circ} \mathrm{W}$.

The difference field for DIF-3 shows a hightemperature tendency across most of the WNP (Fig. 6c). Throughout the typhoon season, there are anomalous positive SSTs with two peaks, one along the equator in the central Pacific and one east of Hawaii $\left(20^{\circ} \mathrm{N}, 130^{\circ} \mathrm{W}\right)$. Part of the anomalous positive SST area reaches the southeastern area in the WNP $\left(0^{\circ}-20^{\circ} \mathrm{N}, 150^{\circ} \mathrm{E}-180^{\circ}\right)$. The hightemperature tendency also appeared in the south part of the South China Sea during the typhoon season.
In summary, the SST in the WNP is high (low) in the HFPs (LFPs). Regions where the SST difference between HFPs and LFPs exceed $0.2^{\circ} \mathrm{C}$ exist in central areas of the tropical WNP $\left(0^{\circ}-10^{\circ} \mathrm{N}\right.$, $140^{\circ} \mathrm{E}-160^{\circ} \mathrm{E}$ ) in $\mathrm{H} 6172$, and in the south part of the South China Sea and in the southeastern area of the WNP $\left(0^{\circ}-20^{\circ} \mathrm{N}, 150^{\circ} \mathrm{E}-180^{\circ}\right)$ in $\mathrm{H} 8694$. Each difference is statistically significant at $95 \%$.

\subsection{Variations of relative vorticity at $850 \mathrm{hPa}$ and divergence at $200 \mathrm{hPa}$}

Next, main features of relative vorticity at 850 $\mathrm{hPa}$ and horizontal wind divergence at $200 \mathrm{hPa}$ are described as representative atmospheric fields associated with TC genesis. In the same way as in the case of SST, we have calculated differences for three combinations of two consecutive periods (Figs. 7 and 8).

The difference of relative vorticity at $850 \mathrm{hPa}$ for DIF-1 shows anomalous positive vorticity between $10^{\circ} \mathrm{N}$ and $30^{\circ} \mathrm{N}$ and anomalous negative vorticity equatorward of $10^{\circ} \mathrm{N}$ in the WNP during the typhoon season (Fig. 7a). Moreover, both centers of the negative and positive areas with statistical significance of $95 \%$ are aligned along $10^{\circ} \mathrm{N}$ between $140^{\circ} \mathrm{E}$ and $150^{\circ} \mathrm{E}$. However, the anomalous positive vorticity northeast of the Philippines is small and the statistical significance is low.

In DIF-2, anomalous negative vorticity extends along $20^{\circ} \mathrm{N}$. These areas of anomalous negative vorticity, with statistical significance of $95 \%$, are located in the northern part of the South China Sea (between $10^{\circ} \mathrm{N}$ and $16^{\circ} \mathrm{N}$ ), northeast of the Philippines (near $20^{\circ} \mathrm{N}, 130^{\circ} \mathrm{E}$ ) and in the area near $20^{\circ} \mathrm{N}$, $160^{\circ} \mathrm{E}$ (Fig. 7b). On the other hand, areas of anomalous positive vorticity with statistical significance are located in the sea areas near $5^{\circ} \mathrm{N}, 160^{\circ} \mathrm{E}$, near $35^{\circ} \mathrm{N}, 165^{\circ} \mathrm{E}$, and near the Ryukyu Islands. This spatial pattern of DIF-2 is opposite that of DIF-1 in the WNP.

In DIF-3, anomalous positive vorticity occupies the subtropical WNP (between $10^{\circ} \mathrm{N}$ and $20^{\circ} \mathrm{N}$ ) and anomalous negative vorticity is located in the tropical WNP (equatorward of $10^{\circ} \mathrm{N}$ ), as shown in Fig. 7c. The difference south of Japan is also negative. In the South China Sea, the pattern of DIF-3 differs from that of DIF-1, and the statistical significance of the anomalous vorticity is also low.

In summary, on anomalous relative vorticity at $850 \mathrm{hPa}$, the difference in the subtropical WNP is positive (negative), and differences in the tropical WNP and south of Japan are negative (positive) 

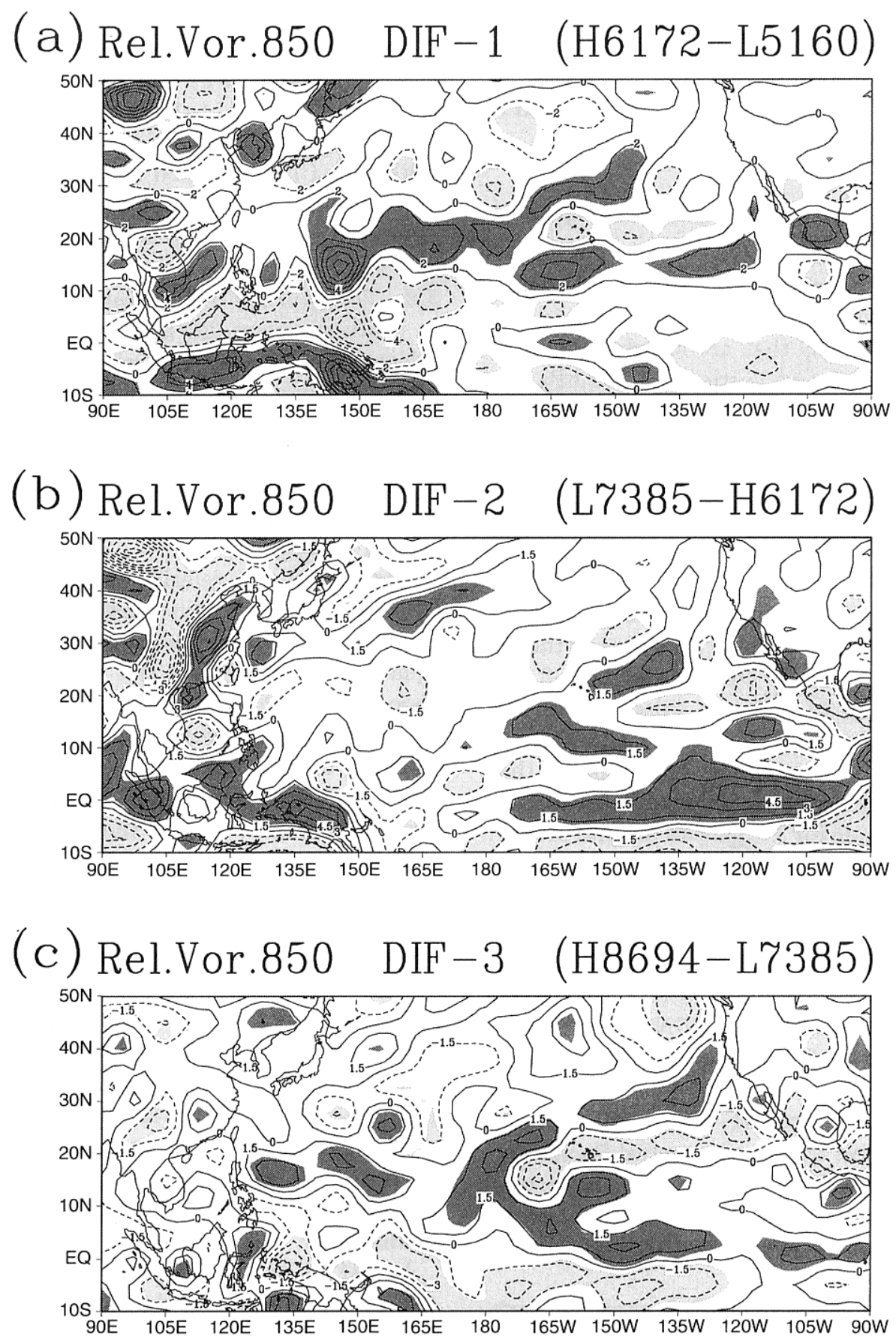

Fig. 7. Distribution of the differences of relative vorticity at $850 \mathrm{hPa}$ for DIF-1, DIF-2, and DIF-3. Shaded areas are statistically significant at $95 \%$ (dark shaded for anomalous positive vorticity and light shaded for anomalous negative vorticity). Contour interval is $2 \times 10^{-6} \mathrm{~s}^{-1}$. 

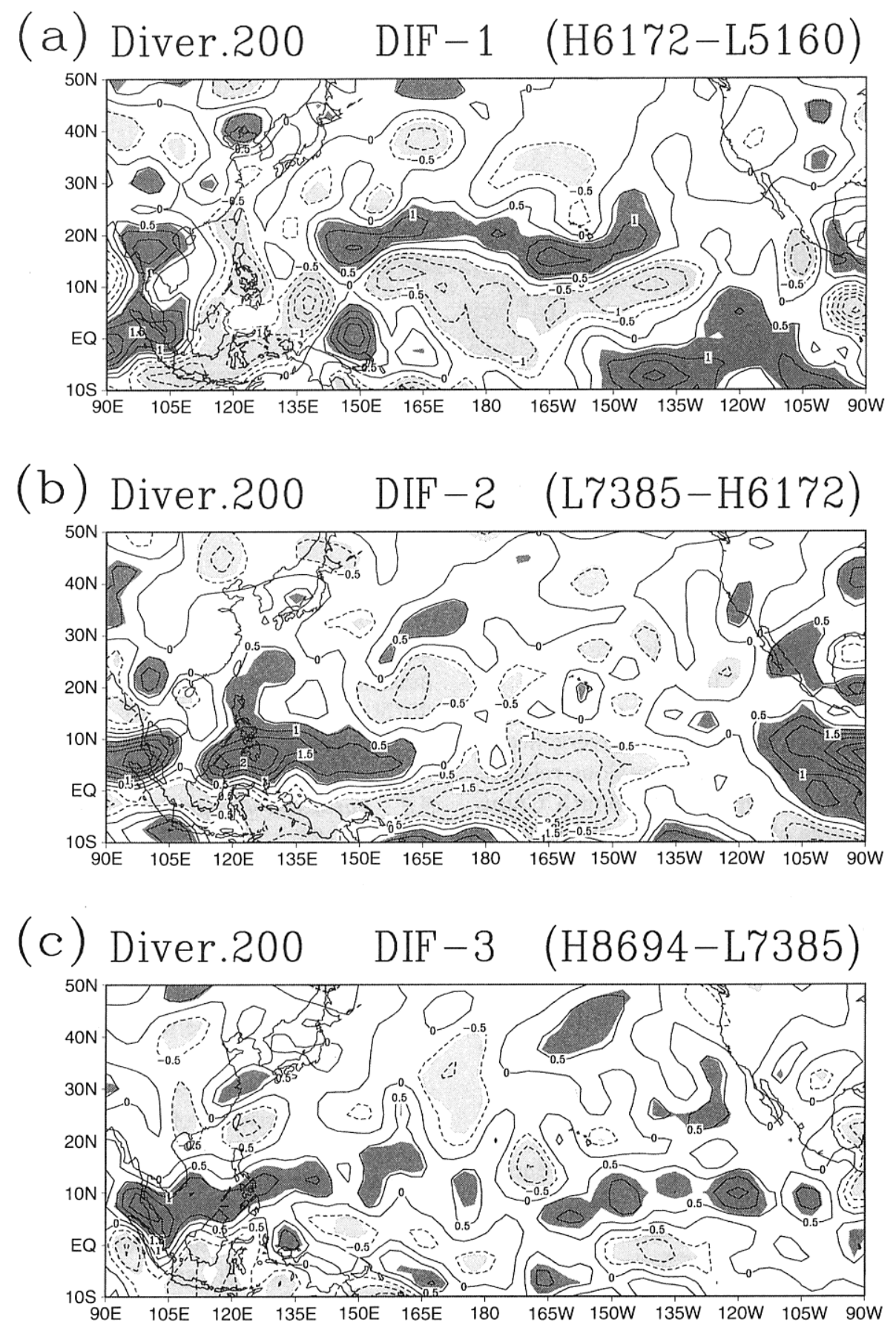

Fig. 8. Distribution of the differences of divergence at $200 \mathrm{hPa}$ for DIF-1, DIF-2, and DIF-3. Shaded areas are statistically significant at $95 \%$ (dark shaded for anomalous positive divergence and light shaded for anomalous negative divergence). Contour interval is $0.5 \times 10^{-6} \mathrm{~s}^{-1}$. 


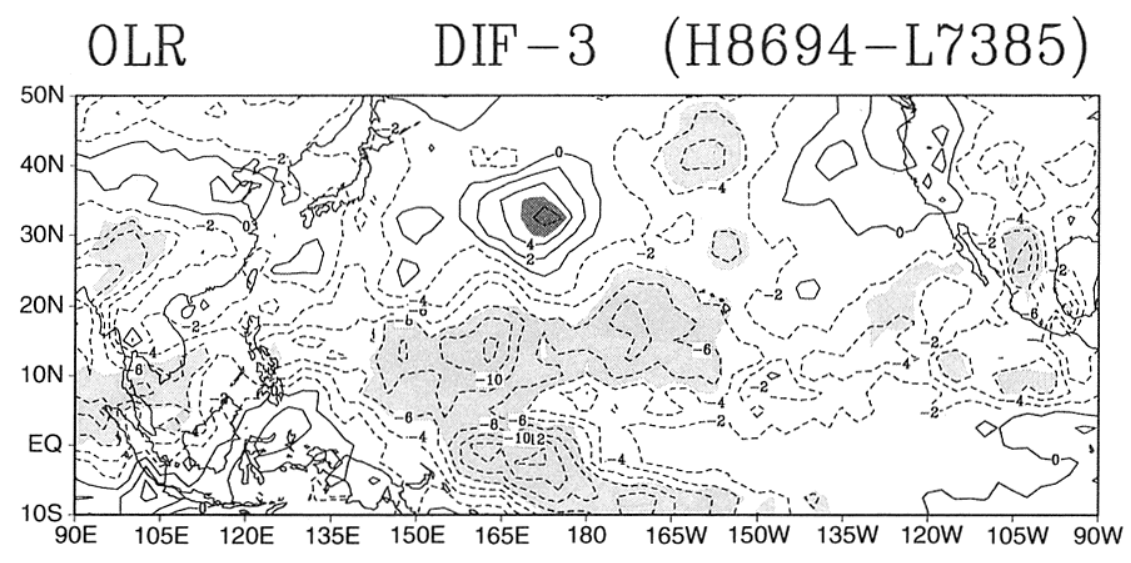

Fig. 9. Distribution of the difference of OLR for DIF-3. Contour interval is $2 \mathrm{~W} \mathrm{~m}^{-2}$ and shaded areas are statistically significant at $95 \%$ (dark shaded for anomalous positive OLR and light shaded for anomalous negative OLR).

in HFP (LFP). However, the spatial pattern of the positive peak with statistical significance of $95 \%$ in DIF-3 is different from that in DIF-1.

Turning to the horizontal wind divergence at 200 $\mathrm{hPa}$, the spatial pattern of anomalous divergence in DIF-1 is similar to that of the anomalous relative vorticity at $850 \mathrm{hPa}$, except for the South China Sea (Fig. 8a). An area of anomalous positive divergence spreads in the subtropical WNP along $20^{\circ} \mathrm{N}$ and east of $135^{\circ} \mathrm{E}$, with a peak in the area near $15^{\circ} \mathrm{N}, 145^{\circ} \mathrm{E}$. On the other hand, anomalous negative divergence appears around the Philippines.

In DIF-2, statistically significant anomalous positive divergence spreads equatorward of $10^{\circ} \mathrm{N}$ and west of $165^{\circ} \mathrm{E}$, mainly above Mindanao in the Philippines (Fig. 8b). Anomalous negative divergence appears prominently in the subtropical WNP (between $10^{\circ} \mathrm{N}$ and $25^{\circ} \mathrm{N}$ ) and east of $150^{\circ} \mathrm{E}$, and the negative center exists near $20^{\circ} \mathrm{N}, 160^{\circ} \mathrm{E}$ during the typhoon season.

In DIF-3, anomalous positive divergence generally appears zonally between $10^{\circ} \mathrm{N}$ and $20^{\circ} \mathrm{N}$ (Fig. $8 \mathrm{c}$ ). The anomalous positive divergences, with statistical significance of $95 \%$ are in the southern part of the South China Sea and east of the Philippines, and are scattered in areas at $20^{\circ} \mathrm{N}, 160^{\circ} \mathrm{E}$ and at $10^{\circ} \mathrm{N}, 170^{\circ} \mathrm{E}$. Anomalous negative divergences appear in the tropical WNP (equatorward of $10^{\circ} \mathrm{N}$ ), and in the area between $20^{\circ} \mathrm{N}$ and $30^{\circ} \mathrm{N}$.

The various observations described in the last few paragraphs have revealed that anomalous positive (negative) divergences dominate over the sub- tropical WNP (between $10^{\circ} \mathrm{N}$ and $20^{\circ} \mathrm{N}$ ) in HFPs (LFPs). The anomalous positive divergences with statistical significance of $95 \%$ in HFPs appear near $20^{\circ} \mathrm{N}, 145^{\circ} \mathrm{E}$ in DIF- 1 and between $10^{\circ} \mathrm{N}$ and $20^{\circ} \mathrm{N}$ in DIF-3.

\subsection{Variation of outgoing longwave radiation (OLR)}

The difference of convective activity in DIF-3 is examined using the data of OLR (Fig. 9). The OLR comparison is examined only in DIF-3, because the OLR data was collected in, and after, June of 1974 . The averaged OLR of L7385 was calculated without the data of 1978 , because they were unavailable.

As indicated in Fig. 9, anomalous negative OLR appears equatorward of $20^{\circ} \mathrm{N}$ between $140^{\circ} \mathrm{E}$ and $155^{\circ} \mathrm{W}$. A part of anomalous negative OLR with statistical significance of $95 \%$ covers the southeastern part of the WNP. In general, anomalous positive OLR extends south of Japan, poleward of $20^{\circ} \mathrm{N}$. Therefore, the convection in H8694 is more active than that in L7385 in the WNP east of $140^{\circ} \mathrm{E}$.

\section{Discussion}

We now discuss the variability of the annual number of TCs in relation to differences of SST, relative vorticity at $850 \mathrm{hPa}$, and divergence at $200 \mathrm{hPa}$ for each period, respectively, following the description in Section 3. First, SSTs in DIF-1 and DIF-3 are anomalously high in the central and eastern tropical Pacific, which means that SSTs of HFPs are 
higher than those of corresponding LFPs. Equatorward of $10^{\circ} \mathrm{N}$ between $140^{\circ} \mathrm{E}$ and $160^{\circ} \mathrm{E}$, the SST of $\mathrm{H} 6172$ is $0.2^{\circ} \mathrm{C}$ higher than that of L5160 and the anomalous positive SST is statistically significant during the typhoon season. Two areas of anomalous positive vorticity at $850 \mathrm{hPa}$ are located on the north and south sides of the anomalous positive SST. Anomalous positive divergence at $200 \mathrm{hPa}$ appears over the area corresponding to the area of the anomalous positive vorticity at $850 \mathrm{hPa}$. In short, these conditions indicate more convectively active conditions; the convergence at $850 \mathrm{hPa}$, the ascent, and the divergence at $200 \mathrm{hPa}$ on the north and south sides of the anomalous positive SST.

In DIF-3, anomalous positive SST with statistical significance extends to the southeastern part of the WNP $\left(0^{\circ}-20^{\circ} \mathrm{N}, 150^{\circ} \mathrm{E}-180^{\circ}\right)$. Anomalous positive vorticity at $850 \mathrm{hPa}$ and anomalous positive divergence at $200 \mathrm{hPa}$ are located in the area $10^{\circ} \mathrm{N}-20^{\circ} \mathrm{N}, 120^{\circ} \mathrm{E}-170^{\circ} \mathrm{W}$ over the western side of the anomalous positive SSTs as a Rossby wave response. Anomalous negative OLR with statistical significance of $95 \%$ also indicates active convection equatorward of $20^{\circ} \mathrm{N}$ between $140^{\circ} \mathrm{E}$ and $155^{\circ} \mathrm{W}$. In short, as in the case of DIF-1, it is suggested that the atmospheric conditions during $\mathrm{H} 8694$ are more convective than those during L7385 in the WNP. In particular, the anomalous positive vorticity at $850 \mathrm{hPa}$, and the anomalous positive divergence at $200 \mathrm{hPa}$, are statistically significant after August (not shown). Thus, it is observed that anomalous positive SST with statistical significance occurred in both HFPs and affected the atmospheric conditions. The convection becomes active due to high SSTs because they warm the lower atmosphere and then the warmed and humid air rises. However, while high SSTs lead to vigorous convection, that convection is not generally organized into TCs unless the positive vorticity at $850 \mathrm{hPa}$ and the positive divergence at $200 \mathrm{hPa}$ are present. This shows that the other factors described by Gray (1968) are also as important, or more important, than the high SST.

With respect to the response of the atmosphere to the oceanic heat source, Webster (1981) indicated that a cyclonic circulation occurred to the north of the heat source in the lower atmosphere, accompanied by Rossby waves when the source was located north of the equator. Then, an anticyclonic circulation was generated in the upper troposphere. Actually in DIF-1, the anomalous positive SSTs with statistical significance in the area $8^{\circ} \mathrm{S}-12^{\circ} \mathrm{N}$, $140^{\circ} \mathrm{E}-160^{\circ} \mathrm{E}$ (Fig. 6a) have induced low level cyclonic circulations in both Hemispheres (Fig. 7a) below the divergence of the upper troposphere (Fig. 8a). Therefore, the relationship between SST, relative vorticity, and divergence corresponds to the response of the atmosphere to the heat source off the equator. Graham and Barnett (1987) found that a dramatic change in convection regimes occurred at a critical SST of about $27.5^{\circ} \mathrm{C}$, and surface wind convergence (divergence) was closely associated with the presence (absence) of deep convection when SSTs were above $27.5^{\circ} \mathrm{C}$. These conclusions were based on observations of SST, atmospheric convection and surface wind divergence from the tropical Indian, Pacific and Atlantic oceans.

Figure 5 indicates that more TCs occurred over the area $10^{\circ} \mathrm{N}-30^{\circ} \mathrm{N}, 130^{\circ} \mathrm{E}-170^{\circ} \mathrm{E}$, except for the area $20^{\circ} \mathrm{N}-30^{\circ} \mathrm{N}, 140^{\circ} \mathrm{E}-150^{\circ} \mathrm{E}$, in DIF-1 and in DIF-3. In particular, the difference of the incidence of TC genesis is prominent over the area $10^{\circ} \mathrm{N}-20^{\circ} \mathrm{N}, 130^{\circ} \mathrm{E}-170^{\circ} \mathrm{E}$. The atmospheric and oceanic conditions in these areas correspond to anomalous convection over the western side of anomalous positive SSTs. These anomalous conditions are favorable for $\mathrm{TC}$ genesis. The differences between HFP and LFP are caused by the anomalous conditions of the atmosphere and the ocean in the tropical WNP.

High SST is not only one of the generating factors of TCs, but is also a driving force of the tropical atmospheric circulation. The variability of SST may cause the atmospheric convection and surface wind divergence to change. The long-term variability of SST in the Pacific may be an important player for the long-term variability of large-scale field of the atmosphere.

On long-term variability of SST, the decadalinterdecadal variability of global mean SST (GMSST) is well known (Kawamura 1994; Lau and Weng 1999). GMSST has increased by about $0.1{ }^{\circ} \mathrm{C}$ during the past 40 years since 1955 . Superimposed on the linear trend is a relatively fast warming during the past 20 years of about $0.2-0.3{ }^{\circ} \mathrm{C}$, which is associated with the advent of the warm phase of a decadal-interdecadal oscillation (Lau and Weng 1999). In particular, SST of the tropics was also warmer (by $0.3{ }^{\circ} \mathrm{C}$ ) in the $1980 \mathrm{~s}$ than in the $1970 \mathrm{~s}$, and the convective activity in the tropics of the Indian Ocean and the central Pacific became more enhanced, corresponding to the rising tropical SST (Nitta and Yamada 1989). Lau and Weng (1999) 
also reported that the tropical eastern Pacific and Indian Oceans were warmed relative to the western Pacific, leading to a relaxation of the climatological east-west SST gradient, in the first annual EOF mode.

In Fig. 6c, the spatial SST pattern of DIF-3 reflects the SST pattern of the decadal-interdecadal oscillation. This is especially evident in the area of positive SST that extends from the central to eastern Pacific in H8694. This rising of SST may activate the convection in the vicinity of the central and eastern Pacific. This condition may also expand over the tropical WNP (equatorward of $10^{\circ} \mathrm{N}$ ) and east of $160^{\circ} \mathrm{E}$, spread the area of TC genesis over the area, and increase the annual number of TCs, as in H8694. Thus, TC activity in the WNP may be affected by decadal-interdecadal oscillations of the ocean and the corresponding variability of atmospheric conditions.

\section{Conclusion}

As a result of examining interdecadal variability of TC activity in the WNP during the 49-yr period 1951-99, we classified the varying frequency of TC genesis by two different categories; two High Frequency Periods (HFPs) in which the annual number of TCs exceeded the average annual number, and two Low Frequency Periods (LFPs) in which it was less than the average annual number. HFPs and LFPs appear alternately, and each period lasts for 10-13 years. The comparison of the monthly average number of TCs between HFPs and LFPs shows that the interdecadal variability depends on the number of TCs during the typhoon season, because the largest difference of TC genesis frequency between both periods has clearly appeared in this season. The variation of TC genesis frequency in HFP is closely related to changes in the oceanic and atmospheric conditions in the WNP. In HFP, the SST is $0.2^{\circ} \mathrm{C}$ or more higher than that in LFP. At the same time, anomalous relative vorticity at 850 $\mathrm{hPa}$ and anomalous divergence at $200 \mathrm{hPa}$ dominate over the western side of the warm sea area.

This atmospheric condition favors deep convection around the anomalous positive SSTs, which appears to lead to an increase in the number of TCs. Only one case during the transition from HFP to LFP showed that when SSTs decrease, deeper convective differences were located equatorward of $10^{\circ} \mathrm{N}$. Along $20^{\circ} \mathrm{N}$, anomalous negative divergence at $200 \mathrm{hPa}$ and cooler than normal SSTs were dominant in DIF-2. These features of the oceanic and atmospheric conditions inhibit TC formation. Comparing the conditions of the atmosphere and the ocean between HFPs and LFPs, we can conclude that the atmospheric and oceanic conditions in the subtropical WNP are more favorable for TC genesis in HFP and less favorable in LFP.

After H8694, TC activity in the 4-yr period 199596, 1998-99 was below normal. Mean SST anomalies during the typhoon season from 1995 to 1997 were negative east of $135^{\circ} \mathrm{E}$ (not shown). Moreover, the relative vorticity anomalies at $850 \mathrm{hPa}$ and the divergence anomalies at $200 \mathrm{hPa}$ during the typhoon season from 1995 to 1999 were also negative between $10^{\circ} \mathrm{N}$ and $20^{\circ} \mathrm{N}$ (not shown). It may be said that the oceanic and atmospheric conditions in the WNP were less favorable for TC genesis in these recent years.

The interdecadal variability of the annual number of TCs in the WNP discussed in this study is based on the observational data of TC activity and on the oceanic and atmospheric conditions. There are close relationships between general TC activity and the oceanic and atmospheric conditions. There is another method that can be used to help explain the interdecadal variability of TC activity. This method analyzes simulations with a high-resolution coupled general circulation model. It is expected that the influence of the oceanic and atmospheric environmental conditions on the interdecadal variability of TC activity will be more clearly explained by comparing the results of the model with observations.

\section{Acknowledgments}

We thank Dr. Ryuichi Kawamura of Toyama University, and Mr. Satoshi Iizuka of the National Research Institute for Earth and Disaster Prevention for their useful discussions and comments. We sincerely thank the two anonymous reviewers who gave valuable comments and suggestions to clarify the manuscripts. We also thank the JMA for supplying data on tropical cyclones in the WNP. We used the NCEP Reynolds historically reconstructed SST data set (available at ftp: //podaac.jpl.nasa. gov/pub/sea _ surface _ temperature/reynolds/rsst/ data/) and the NCEP/NCAR Reanalysis data set (available at http: //wesley.wwb.noaa.gov/ncep_ data/index_sgi62_png.html) for this study. We would like to extend our gratitude to these organizations. 


\section{References}

Aoki, T., 1983: Geographical and long-term variations in the western North Pacific Typhoons. Pap. Meteor. Geophys., 34, 143-150 (in Japanese with English Abstract).

, 1985: A climatological study of typhoon formation and typhoon visit to Japan. Pap. Meteor. Geophys., 36, 61-118.

Becker, R.A., J.M. Chambers, and A.R. Wilks, 1988: The new $S$ language. A programming environment for data analysis and graphics. Wadsworth \& Brooks/Cole, California. xvii+702 pp.

Chan, J.C.-L., 1995: Tropical cyclone activity in the western North Pacific in relation to the stratospheric quasi-biennial oscillation. Mon. Wea. Rev., 123, 2567-2571.

and J. Shi, 1996: Long-term trends and interannual variability in tropical cyclone activity over the western North Pacific. Geophys. Res. Lett., 23, 2765-2767.

Graham, N.E. and T. P. Barnett, 1987: Sea surface temperature, surface wind divergence, and convection over tropical oceans. Science, 238, 657659.

Gray, W.M., 1968: Global view of the origin of tropical disturbances and storms. Mon. Wea. Rev., 96, 669-700.

1984: Atlantic seasonal hurricane frequency. Part I: El Niño and $30 \mathrm{mb}$ Quasi-Biennial Oscillation influences. Mon. Wea. Rev., 112, 16491668 .

Japan Meteorological Agency, 1991-1999: Geophysical Review. nos. 1097-1204, Japan Meteorological Agency (in Japanese).

Kalnay, E., M. Kanamitsu, R. Kistler, W. Collins, D. Deaven, L. Gandin, M. Iredell, S. Saha, G. White, J. Woollen, Y. Zhu, M. Chelliah, W. Ebisuzaki, W. Higgins, J. Janowiak, K.C. Mo, C. Ropelewski, J. Wang, A. Leetmaa, R. Reynolds, R. Jenne, and D. Joseph, 1996: The NCEP/NCAR 40-year reanalysis project. Bull. Amer. Meteor. Soc., 77, 437-471.

Kawamura, R., 1994: A rotated EOF analysis of global sea surface temperature variability with interannual and interdecadal scales. J. Phys. Oceanogr., 24, 707-715.

Lander, M.A., 1994: An exploratory analysis of the relationship between tropical storm formation in the western North Pacific and ENSO. Mon. Wea. Rev., 122, 636-651. and C.P. Guard, 1998: A look at global tropical cyclone activity during 1995: contrasting high Atlantic activity with low activity in other basins. Mon. Wea. Rev., 126, 1163-1173.

Landsea, C.W., N. Nicholls, W.M. Gray, and L.A. Avila, 1996: Downward trends in the frequency of intense Atlantic hurricanes during the past five decades. Geophys. Res. Lett., 23, 1697-1700.

Lau, K.-M. and H. Weng, 1999: Interannual, decadalinterdecadal, and global warming signals in sea surface temperature during 1955-97. J. Climate, 12, 1257-1267.

Matsuura, T., M. Yumotö, S. lizuka, and R. Kawamura, 1999: Typhoon and ENSO simulation using a high-resolution coupled GCM. Geophys. Res. Lett., 26, 1755-1758.

McBride, J.L. and R. Zehr, 1981: Observational analysis of tropical cyclone formation. Part II: Comparison of non-developing versus developing systems. J. Atmos. Sci., 38, 1132-1151.

Nitta, T. and S. Yamada, 1989: Recent warming of tropical sea surface temperature and its relationship to the Northern Hemisphere circulation. $J$. Meteor. Soc. Japan, 67, 375-383.

Raper, S.C.B., 1993: Observational data on the relationships between climate change and the frequency and magnitude of severe tropical storms. Climate and sea level change: observations, projections and implications, edited by R.A. Warrick, E.M. Barrow, and T.M.L. Wigley, Cambridge University Press, 192-212.

Ritchie, E.A. and G.J. Holland, 1999: Large-scale patterns associated with tropical cyclogenesis in the western Pacific. Mon. Wea. Rev., 127, 20272043.

Regional Specialized Meteorological Center TokyoTyphoon Center, 1992: Tropical cyclone tracks in the western North Pacific 1951-1990. Japan Meteorological Agency, 192 pp.

Shapiro, L.J., 1989: The relationship of the quasibiennial oscillation to Atlantic tropical storm activity. Mon. Wea. Rev., 117, 1545-1552.

Tukey, J.W., 1977: Exploratory Data Analysis. Addison-Wesley, Reading, Massachusetts. 688 pp. + xvi.

Velleman, P.F, and D.C. Hoaglin, 1981: Applications, basics, and computing of exploratory data analysis. Duxbury Press, Boston, Massachusetts. xxi +354 pp.

Webster, P.S., 1981: Mechanisms determining the atmospheric response to sea surface temperature anomalies. J. Atmos. Sci., 38, 554-571. 